Bond University

Research Repository

\title{
Effects of consumers' construal levels on post-impulse purchase emotions
}

Togawa, Taku; Ishii, Hiroaki; Onzo, Naoto; Roy, Rajat

Published in:

Marketing Intelligence and Planning

DOI:

10.1108/MIP-01-2019-0022

Licence:

CC BY-NC

Link to output in Bond University research repository.

Recommended citation(APA):

Togawa, T., Ishii, H., Onzo, N., \& Roy, R. (2020). Effects of consumers' construal levels on post-impulse purchase emotions. Marketing Intelligence and Planning, 38(3), 269-282. https://doi.org/10.1108/MIP-01-20190022

\section{General rights}

Copyright and moral rights for the publications made accessible in the public portal are retained by the authors and/or other copyright owners and it is a condition of accessing publications that users recognise and abide by the legal requirements associated with these rights.

For more information, or if you believe that this document breaches copyright, please contact the Bond University research repository coordinator. 


\title{
Effects of Consumers' Construal Levels on Post-Impulse Purchase Emotions
}

\begin{abstract}
Purpose: This study examines how abstract versus concrete mindsets impact consumers' postpurchase affective states. Drawing on construal level theory, the study examines when consumers experience 'pleasure' or 'guilt' after impulse buying.

Design/methodology/approach: The basic premises of this research was tested using multiple studies. Study 1 was conducted in the field, the second study engaged an online survey, while the third study was a laboratory experiment.
\end{abstract}

Findings: After impulse buying, consumers with abstract mindsets reported strong feelings of pleasure, whereas those with concrete mindsets experienced profound guilt.

Research limitations/implications: Research on affective responses (i.e. pleasure and guilt) following impulse purchase is limited. However, the present study helps understand an important research question: When do consumers feel pleasure (or guilt) after impulse buying?

Practical implications: Marketers can frame messages that align with abstract mindsets to enhance pleasure and reduce guilt after impulse buying.

Social implications: Policy makers can persuade consumers to refrain from making impulsive decisions through communication that reminds them of past impulse purchase behaviour, by triggering a concrete mindset.

Originality/value: This research extends the literature on post-purchase effects by demonstrating that consumers' mindsets determine the intensity of their affective state after impulse buying.

Keywords: Impulse buying, Pleasure, Guilt, Abstract mindset, Concrete mindset

Type: Research paper 


\section{Introduction}

Consumers often recall their shopping experiences and accompanying emotions (Bui et al., 2009; Lee and Tsai, 2013; Richins, 1997), for instance, when posting about them in social media or completing customer surveys. A body of literature has identified post-purchase emotions such as satisfaction (e.g. Oliver, 2010; Oliver and Swan, 1989), delight (e.g., Chitturi et al., 2008), regret (e.g. Bui et al., 2009; Chu et al., 2013), and pleasure/happiness (e.g. Alba and Williams, 2012). Since most (70-80\%) purchase decisions are made in-store (Bell et al., 2011; Hui et al., 2013; Underhill, 2000), some researchers focused on consumer emotional states evoked by impulse buying. These studies show that two affective states result from impulse buying: pleasure and guilt (Gardner and Rook, 1988; Goldsmith et al., 2012; Mukhopadhyay and Johar, 2007).

While extant research has investigated the types of emotion evoked after impulse purchases, it has not considered when consumers strongly feel the specific post-impulse purchase emotions. Since psychological literature suggests that people's emotions are not always stable, but changes over time (Houben, Noortgate, and Kuppens 2015; Kuppens, Oravecz, and Tuerlinckx 2010; Larsen 1987), it is expected that the intensity of post-impulse purchase emotion can also vary depending on various factors. If so, more research is needed to identify the boundary conditions of post-impulse-buying affective states and therefore examine when consumers experience positive/negative emotions post impulse purchase.

This study uses construal level theory to identify the boundary condition of consumers' postpurchase affective states. This theory posits that when people feel psychologically distant from an object, their mindsets become more abstract; they focus on its abstract and goal-relevant elements. Contrastingly, when the object is psychologically near, people have concrete mindsets and focus more on concrete and goal-irrelevant attributes of the object (Liberman and Trope, 
2008; Trope and Liberman, 2003, 2010; Trope et al., 2007). For instance, when consumers imagine purchasing a laptop in the distant (near) future, they tend to have a more abstract (concrete) mindset and focus on more abstract (vs. concrete) attributes of the product. For example, they can focus on either abstract (brand image, product design) or concrete attributes (e.g. weight, portability, and usability) in their purchase decision. The abstract versus concrete mindset has been shown to influence consumers' decision making (e.g., Xu, Jiang, and Dhar 2013; MacDonnell and White 2015). Based on this theory, the current study focuses on two types of affective states (i.e. pleasure and guilt) and investigates the impact of consumers' construal level on their affective state after impulse buying. Using three studies, this research shows that while pleasure is more likely to impact consumers with abstract (versus concrete) mindsets, consumers with concrete (versus abstract) mindsets are more likely to experience guilt.

Our study contributes to the literature in several ways. First, consumers' affective states evoked by past shopping experiences influence their repurchase intentions, word-of-mouth (Chitturi et al., 2008), brand (or store) loyalty (Chaudhuri and Holbrook, 2001), and subsequent decision-making (Hasford et al., 2015). Thus, identifying the boundary conditions of postimpulse purchase emotion helps to better understand and more accurately predict consumers' responses. To the best of our knowledge, this is the first study to show that post-impulse purchase emotion varies depending on consumers' construal mindsets. Second, our research helps consider fundamental questions about consumers' self-control failure. For instance, even though consumers may have experienced not only pleasure but guilt during past impulse-buying episodes, why is it difficult to refrain from such behaviours? Conversely, why do consumers experience intense guilt even though they may have been pleased with their past impulse-buying experience? Our research provides clues to answer these questions by showing how consumers 
with abstract versus concrete mindsets view their purchasing experiences, and how their perspectives influence their affective states. Finally, the results contribute to the extensive body of construal level literature, suggesting that construal mindsets (abstract versus concrete) predict not only consumers' decision-making on future purchasing but also evaluate their past shopping experiences.

\section{Theoretical Background}

\section{Consumers' Affective States after Impulse Buying}

Generally, impulsive buying provides an opportunity to experience both pleasure and pain associated with the buying behaviour (Rook 1987). The feeling of pleasure includes related emotions such as 'feeling good' and 'happiness' evoked through self-indulgence and acquiring something for oneself. Consumers also experience pain due to financial (e.g. waste of money) and psychological (e.g. self-control failure) problems after impulse buying. Research shows that 'the impulse to buy is hedonically complex and may stimulate emotional conflict' (Rook 1987, p.191).

Some studies focused on the act of impulse buying and associated changes generated in consumers' affective states. For example, in an interview conducted by Rook (1987), 29\% of participants cited mixed emotions such as pleasure evoked after purchasing an attractive product, while acknowledging the reality of refraining from indulgence after impulse buying. During the interview, most consumers reported that impulse buying resulted in increased feelings of both pleasure and guilt. Rook (1987) also reported that because consumers derive positive, hedonic feelings such as pleasure through impulse buying, it is likely that they also experience negative feelings such as pain and guilt for exceeding their budgets or breaking norms.

Gardner and Rook (1988) confirmed that consumers experience both pleasure and guilt after 
impulse buying. According to Mukhopadhyay and Johar (2007), consumers had strong feelings of pleasure and guilt accompanied by regret after impulse buying, whereas those who refrained from impulse buying experienced a strong feeling of pride. Similarly, Goldsmith et al. (2012) reported that consumers feel both pleasure and guilt after hedonic, indulgent consumption.

The question is, why do these affective states occur after impulse buying? Literature on goalbased appraisals answers this question (Mukhopadhyay and Johar, 2007). According to this framework, specific types of affective states are caused by distinct cognitive appraisals (Zeelenberg et al., 2008) related to specific motivational goals and actions (Roseman et al., 1994). As an initial work, Roseman (1991) documented specific types of affect based on a combination of outcomes (e.g. reward/punishment) and cause (e.g. circumstances/self/others). For instance, people tend to feel joy when obtaining a certain reward when they deserve it: a positive outcome. Similarly, people experience pride when they earn self-caused, punishmentabsent outcomes such as achieving academic goals, winning games.

This framework explains consumers' affective states after engaging in or refraining from impulse buying. Specifically, it is assumed that while pleasure is derived from a certain reward (i.e. item purchased), guilt develops from deserved punishment caused by one's actions (i.e. unplanned spending). People are likely to feel pride after refraining from impulse buying, since they obtained self-caused, punishment-absent outcomes (i.e. protecting their self-regulated goal of not spending).

Although previous studies have reported other types of emotions, such as excitement (Gardner and Rook 1988), the current study focuses on two types of affective states commonly reported in the literature on post-impulse purchase affect: pleasure and guilt. The next section draws on construal level theory and presents a discussion of when consumers experience strong (or weak) 
feelings of pleasure and guilt after impulse buying.

\section{Construal Level Theory}

Construal level theory (Trope and Liberman, 2003, 2010; Trope et al., 2007) posits that when individuals feel psychologically distant from an object, they form abstract mindsets (high-level construal), focusing on superordinate, goal-relevant features and desirability of the object. In contrast, when the object is psychologically near, they form more concrete mindsets (low-level construal), focusing more on subordinate, goal-irrelevant attributes and feasibility of the object (Trope and Liberman, 2010; Trope et al., 2007).

Construal level theory explains various phenomena regarding consumers' cognitive and behavioural characteristics. For example, while shopping for an MP3 player in the distant future, a consumer may focus on sound quality (goal-relevant, abstract attribute). However, while shopping for the same MP3 player in the near future (e.g. tomorrow), consumer decision is guided by size and portability (goal-irrelevant, concrete attributes) (Hamilton and Thompson, 2007). While choosing from a large assortment, consumers with abstract (vs. concrete) mindsets perceive the assortment options as more similar and accordingly experience less choice difficulty (Xu, Jiang, and Dhar 2013). When abstract (vs. concrete) mindset is activated, a request for time (vs. money) yields favorable charitable-giving behaviour (MacDonnell and White 2015).

Although the majority of literature on construal level theory focuses on the impact of temporal distance to a future event on people's mindsets, some studies focus on the relationship between temporal distance to a past event and people's mindsets. Kyung, Menon, and Trope (2010) show that a past event, recalled in a concrete mindset, feels closer than when recalled in an abstract mindset.

Past research has manipulated people's construal mindsets by employing a cognitive task 
(e.g. Navon task, why/how task, and category task). For instance, in the Navon (1977) task, participants are presented with large letters composed of small letters and asked to focus on the large letters (abstract mindset) or the small letters (concrete mindset) (see Appendix for examples of stimuli). In the category task, participants are instructed to generate superordinate category labels (abstract mindset) or subordinate exemplars (concrete mindset) for words (e.g. beer, book, professor) (Hansen and Trope, 2013; Lee et al., 2014).

\section{Hypotheses}

Drawing on construal level theory, this study assumes that the intensity of each affective state varies depending on the construal level of previous impulse-buying episodes. It is assumed that consumers have strong feelings of pleasure when impulse buying is construed with an abstract mindset and strong feelings of guilt when construed with a concrete mindset. These assumptions are based on the following three arguments.

First, contradiction may arise during an impulse purchase, as one should typically be motivated to adhere to a descriptive norm (e.g. avoiding wasteful spending), but realizes the purchase has been made. This contradiction is better managed by individuals with abstract mindsets. For example, research shows that those with abstract mindsets have a tendency toward flexible construal of inconsistencies and contradictions between situations (Förster et al., 2004) and are less likely to experience feelings of discomfort when confronting such contradictions, compared to consumers with concrete mindsets (Förster et al., 2004; Hong and Lee, 2010). Since consumers may experience both pleasure and guilt following impulse purchases, the study posits that people with abstract mindsets can handle guilt associated with such purchasing behaviour better than can their counterparts.

Consumers with abstract mindsets, compared to those with concrete mindsets, may not 
experience discomfort when facing the contradiction, and this may enhance their feelings of pleasure. Contrastingly, consumers with concrete mindsets interpret things in detailed and specific terms and pay more attention to contradictions and conflicts (Trope and Liberman, 2003). They become more sensitive to the emotional inconsistencies experienced after the impulse buy and may focus on feelings of guilt for violating existing norms.

Second, whether to focus on the pros or cons of an action depends on the construal level. For instance, through impulse buying, a consumer achieves the goal of 'obtaining the product', but not the goal of 'self-control of wasteful spending' (Mukhopadhyay and Johar, 2007). Since consumers with abstract mindsets tend to focus on the pros of an action (Eyal et al., 2004), doing so should generate strong feelings of pleasure by focusing on the positive feelings associated with obtaining the product. Conversely, since consumers with concrete mindsets tend to focus on the cons of the action (Eyal et al., 2004), doing so is likely to generate strong feelings of guilt by highlighting negative aspects such as not adhering to norms or not regulating spending.

Third, whether to focus on the benefits themselves or the costs incurred to obtain the benefits depends on the construal level. As opposed to those with abstract mindsets, consumers with concrete mindsets focus on the costs incurred to derive these benefits (Bornemann and Homburg, 2011). Therefore, in impulse buying, a consumer with an abstract mindset focuses on the product and its benefits, which is likely to generate strong feelings of pleasure associated with obtaining the product. In contrast, a consumer who focuses on the costs incurred to obtain the product's benefits may focus on the guilt experienced as a result of making an unnecessary expenditure due to impulse buying. Based on the above, the following hypotheses are proposed:

H1: Consumers with abstract mindsets experience greater pleasure after impulse buying (vs. refraining from impulse buying) compared to individuals with concrete mindsets. 
H2 : Consumers with concrete mindsets experience more guilt after impulse buying (vs. refraining from impulse buying) compared to individuals with abstract mindsets.

To test these hypotheses, we conducted three experiments that employed different construal mindsets manipulation: temporal distance (Study 1), Navon task (Study 2), and the category task (Study 3).

\section{Study 1}

Study 1 established that mindsets could influence feelings after an impulse-buying episode. Specifically, the focus is a situation where the consumer indulges in impulse buying at a travel destination (Crawford and Melewar, 2003). As reviewed, most of the research examined the effect of consumers' construal mindsets on their decision by manipulating temporal distance to the purchase goal (e.g., Goodman and Malkoc, 2011; Martin, Gnoth, and Strong, 2009). Following these studies, we investigate how temporal distance to the past impulse purchase affects consumers' affective states. Using the longitudinal method, two surveys at different times were conducted for these consumers. Since the second survey is more temporally distant to impulse buying, it is assumed that the time (i.e. temporal distance) might make consumers' mindsets more abstract and alter their affective states (i.e. pleasure and guilt).

\section{Sample}

In this online survey, the sample comprised 310 consumers living in metropolitan areas in Japan $\left(M_{\mathrm{age}}=41.73,143\right.$ males and 167 females). Sampling conditions were set as follows: (1) they took a domestic trip at least once between July 13 and August 31, 2013; (2) they indulged in impulse buying for themselves (not others) at the destination. Some consumers who impulsively purchased low-priced consumer goods (e.g. snacks, drinks) may forget the details. To prevent this, another condition was set: (3) they spent above JPY 3,000 (around USD 26) on the impulse 
buy.

\section{Method}

Time period 1 (T1). The T1 survey was conducted on September 1, 2013. Respondents were asked to recall their trip and describe the destination and date. Then they identified the category and price of their impulse purchase at the destination. Finally, they explained the pleasure ('I feel pleasure') and guilt ('I feel guilty') they experienced when reminiscing about the purchase using a seven-point scale (' $1=$ Not agree' to ' $7=$ Agree').

Time period 2 (T2). Three months later (December 1, 2013), the T2 survey was conducted. About 48 respondents were excluded, as they described impulse buys below JPY 3,000 in the T1 survey. The remaining 262 respondents were called to participate in the T2 survey, and 200 respondents participated. They were instructed to indicate their feelings of pleasure or guilt when recalling the impulse buy using a seven-point scale. To examine the impact of individual difference on the frequency of impulse buying in the post-purchase affective state, consumers' impulsive buying tendencies were measured ('I often buy things spontaneously') (Rook and Fisher, 1995) using a seven-point scale (' $1=$ Not agree' to ' $7=$ Agree').

\section{Results and Discussion}

About 38 respondents who failed to recall their impulse-buying experiences were excluded. The rest of the sample ( $\mathrm{n}=162)$ was used for analysis. On average, respondents spent approximately JPY 15,000 (USD 132) ( $\left.M_{\text {Price }}=14497\right)$ on their impulse buy, mainly purchasing clothing, bags, cutlery, and souvenirs exclusive to the destination.

Because all study items were measured by self-reported measurements using a single method, the possibility of common method variance (CMV) was addressed from several approaches. In line with Podsakoff et al. (2003), we took several procedural remedies. First, subjects were not 
aware of the study hypotheses and their responses were anonymous. Second, item ambiguity was reduced by avoiding unusual and ambiguous words, and the order of the measurement items was randomized (Malhotra, Kim, and Patil 2006). Third, "temporal separation" of measurement across times $\mathrm{T} 1$ and $\mathrm{T} 2$ was also engaged (Podsakoff et al., 2003). In addition to procedural remedies, we also took statistical remedies to assess the extent to which CMV affected the results. A confirmative factor analysis (CFA) was performed following a recent study (Leckie, Nyadzayo, and Johnson 2016). In the CFA model, all the manifest items were included as the indicators of a single factor representing method effects (Malhotra. Schaller, and Patil 2017). The model indicated poor fit $\left(\chi^{2}=15.312, d f=8, \mathrm{p}<.001, \mathrm{GFI}=.673\right.$, AGFI $=.629, \mathrm{CFI}=.770$, RMSEA $=.075)$. This result suggests that CMV was unlikely to be a serious issue.

Further, multivariate analysis of covariance (MANCOVA) was conducted, with temporal distance (T1 and T2, a within-factor) as an independent variable and affective state (pleasure and guilt) as the dependent variable, controlling the impact of the product's price and impulse-buying tendency as covariates that could influence respondents' post-purchase affective states. Consistent with our hypothesis, temporal distance significantly influenced participants' affective state (Wilks' $\left.\lambda=.855, \mathrm{~F}(1,159)=8.904, \mathrm{p}<.0001, \omega^{2}=.081\right)$. Specifically, the feeling of pleasure in $\mathrm{T} 2$ was higher than in $\mathrm{T} 1\left(M_{\mathrm{T} 1}=4.796\right.$ vs. $\left.M_{\mathrm{T} 2}=5.043, \mathrm{p}<.0001\right)$, whereas the feeling of guilt in $\mathrm{T} 2$ was lower than in $\mathrm{T} 1\left(M_{\mathrm{T} 1}=2.691\right.$ vs. $\left.M_{\mathrm{T} 2}=2.370, \mathrm{p}<.0001\right)$. However, the impact of covariates was insignificant in both pleasure and guilt $(F \mathrm{~s}(1,159)<.100, p \mathrm{~s}$ $\left.>.750 ; \omega^{2} \mathrm{~s}=.001\right)^{1}$.

\footnotetext{
${ }^{1}$ From some perspectives, we can explain the result that impulsive buying tendency had no effect on consumers' affective states. For example, Kacen and Lee (2002) show the effect of impulse buying trait on impulse purchase behaviour is significantly smaller among Asian (vs. Caucasian) consumers. Since our study was conducted with Japanese consumers, there is a possibility that impulse-buying tendencies they reported did not have a strong relationship with their frequency of impulse purchase and did not affect how strongly they felt emotionally afterward.
} 
For Study 1, the results support the hypotheses. In the T2 survey, respondents perhaps felt their impulse buying as more temporally distant than those in the T1 survey and considered the purchases using an abstract mindset. Since respondents with abstract mindsets tend to focus on the pros (versus cons) and benefits (versus costs) of a past shopping experience, they may experience more pleasure and less guilt when recalling their impulse buys in the survey.

As with most field studies, potential threats to internal validity exist. For instance, rather than shifting mindsets, consumers may have reduced cognitive resonance about their decisions (i.e. impulse buying). In addition, there is a possibility that participants' memory about their past impulse purchase distorted from the T1 survey to the T2 survey. To overcome these issues, we conducted Study 2 to measure participants' affective state by a single survey after engaging in a manipulation task of construal mindsets.

\section{Study 2}

\section{Participants and Design}

Study 2 was conducted by using an online survey. In total, 76 consumers $\left(M_{\text {age }}=41.756,51\right.$ males, 21 females, 4 non-responses) participated in the study. The sampling condition was set so they spent above JPY 3,000 for an impulse buy on the last weekend (June 22nd or 23rd, 2019). They were randomly assigned to either the abstract or concrete conditions.

\section{Procedure}

Participants anonymously took part in seemingly unrelated studies. Further, like study 1 , similar measurement procedure (e.g., randomization of items, item ambiguity) was engaged to address common method bias (Podsakoff et al. 2003). First, participants' mindsets were manipulated using a widely used technique from the marketing literature (e.g. Wright et al. 2011). For the manipulation, we adopted the Navon (1977) task, in which large letters composed of small letters 
are presented, and participants were asked to focus on the large letters (abstract condition) or the small letters (concrete condition) (Appendix).

Next, to determine whether this task successfully manipulated participants' mindsets, they were asked to complete Behaviour Identification Form (BIF) items (Vallacher and Wegner, 1989). Participants were given ten activities (i.e., sample activities like paying rent, eating, brushing teeth, measuring a room for carpeting) and offered two ways of identifying each activity. For example, the options for paying rent either maintaining a place to live (abstract, high-level identification) or writing a check (concrete, low-level identification). When participants chose an abstract (vs. concrete) option, the response was replaced with 1 (vs. 0). Participants' responses to all ten actions were summed to create a construal mindsets index ( 0 to 10$)$, where greater values indicate higher (more abstract) construal mindsets. Finally, participants were asked to indicate the feeling of pleasure and guilt when recalling the impulse buying on June 22nd or 23rd using the same scale as Study 1. The product's price and consumer's impulse-buying tendency were also measured as in Study 1. Respondents also provided basic information on their impulse buying (e.g. purchase date, store location) and their demographic information such as gender and age.

\section{Results}

Manipulation check. The construal mindsets index of the abstract condition was significantly higher than that of the concrete condition $\left(M_{\text {Abstract }}=5.743, S D_{\text {Abstract }}=2.112\right.$ versus $M_{\text {Concrete }}=$ 4.702, $\left.S D_{\text {Concrete }}=2.234 ; \mathrm{t}(74)=2.088, \mathrm{p}=.040 ; \mathrm{r}=.236\right)$. Therefore, the manipulation of participants' mindsets via the Navon task was considered successful.

Pleasure and guilt. A one-way MANCOVA was conducted with affective state (pleasure and guilt) as dependent variables, mindsets as the dependent variable, and product price and impulsebuying tendency as covariates. These covariates had no effect on the dependent variables (for 
price, Wilks' $\lambda=.982, \mathrm{~F}(1,70)=.643, \mathrm{p}=.529$; for impulse-buying tendency, Wilks' $\lambda=.978, \mathrm{~F}$ $(1,70)=.779, \mathrm{p}=.463)$. More importantly, mindsets significantly influenced participants' affective state (Wilks' $\lambda=.863, \mathrm{~F}(1,70)=5.475, \mathrm{p}=.006)$. Specifically, participants in the abstract mindset condition $(\mathrm{n}=39)$ reported significantly greater pleasure $\left(M_{\text {Abstract }}=5.132\right.$, $S D_{\text {Abstract }}=1.234$ versus $M_{\text {Concrete }}=4.583, S D_{\text {Concrete }}=1.360 ; \mathrm{F}(1,70)=3.369, \mathrm{p}=.071 ; \eta^{2}$ $=.048)$ and lower guilt $\left(M_{\text {Abstract }}=2.342, S D_{\text {Abstract }}=1.529\right.$ versus $M_{\text {Concrete }}=3.444, S D_{\text {Concrete }}=$ $\left.1.843 ; \mathrm{F}(1,70)=9.515, \mathrm{p}=.003 ; \eta^{2}=.136\right)$ at $5 \%$ or $10 \%$ level, compared with those in the concrete mindset condition $(n=37)$. Thus, the results from Study 1 were successfully replicated in Study 2.

\section{Study 3}

Study 3 used a controlled design to examine whether consumers' mindsets influenced their affective state after an impulse-buying episode.

\section{Participants and Design}

289 Japanese undergraduate students $\left(M_{\text {Age }}=21.26,210\right.$ males, 79 females $)$ participated in the experiment. A 2 (impulse buying: buying/not-buying) $\times 2$ (mindsets: abstract/concrete) betweensubjects' design was engaged, and participants were randomly assigned to one of the four conditions. In this study, participants' mindsets and the buying/not-buying conditions were manipulated using a scenario (Mukhopadhyay and Johar, 2007). This helped provide evidence that the reported affective state (i.e. pleasure and guilt) was evoked by the impulse-buying experience in the scenario.

\section{Procedure}

Participants seemingly took part in unrelated studies and were further briefed that their responses would be anonymous. The issue of common method bias was addressed by adopting 
similar procedural approaches mentioned in previous studies. The experimental procedure comprised of three steps. First, subjects were exposed to the impulse-buying scenario, adapted from extant research (Sultan et al., 2012). Participants were asked to read the following scenario: Imagine you were shopping at a mall in your neighbourhood last week. When you stopped by an apparel shop inside the mall, you found a T-shirt very attractive. The T-shirt was priced at JPY 6000 (around USD 60). Although you felt it was a little expensive, you found the courage to buy it because you were strongly tempted to buy it at that moment (buying condition)/although you were strongly tempted to buy it, you refrained from doing so because you must save money (not-buying condition).

Next, participants' mindsets were manipulated to examine how they construed the feelings (pleasure and guilt) generated by the scenario. They were instructed to engage in a category task to manipulate their mindsets (Hansen and Trope, 2013; Lee et al., 2014). For the abstract mindset condition, five words (spoon, chair, train, baseball, piano) were provided, and participants were asked to write a more abstract, high-level category in each blank (e.g. 'Spoon is an example of '). For the concrete mindset condition, participants were given five words (cutlery, furniture, transportation, sports, musical instrument) and asked to write a concrete, low-level category in each blank (e.g. '___ is an example of cutlery').

After the manipulation task, participants were asked to imagine the scenario again and indicate the pleasure or guilt they felt, using a seven-point scale, similar to the previous experiments. At the end of the experiment, to determine whether the category task successfully manipulated participants' mindsets, they completed the BIF scale as in Study 2. Results 
Overall, ten participants failed to answer questions on their experiences or the BIF scale. They were excluded, and the remaining sample $(n=279)$ was used for the following analysis.

Manipulation check. The construal mindsets index of the abstract condition was significantly higher than the concrete condition $\left(M_{\text {Abstract }}=6.028, S D_{\text {Abstract }}=2.028\right.$ versus $M_{\text {Concrete }}=5.526$, $\left.S D_{\text {Concrete }}=1.959 ; \mathrm{t}(277)=2.104, \mathrm{p}=.036 ; \mathrm{r}=.125\right)$. Therefore, the manipulation of participants' mindsets was considered successful.

Pleasure and guilt. A two-way MANOVA was conducted with impulse buying and mindsets as independent variables and affective state (pleasure and guilt) as dependent variables. The main effect of impulse buying was significant (Wilk's $\lambda=.675, \mathrm{~F}(1,275)=65.819, \mathrm{p}<.001$ ) while the main effect of mindsets was insignificant (Wilk's $\lambda=.990, \mathrm{~F}(1,275)=1.365, \mathrm{p}=.257$ ). Importantly, the interaction between impulse buying and mindsets was significant (Wilk's $\lambda$ $=.958, \mathrm{~F}(1,275)=5.988, \mathrm{p}=.003$; Figure 1). For the condition of buying, participants with abstract mindsets $(n=74)$ reported experiencing greater pleasure and lower guilt than those with concrete mindsets $(\mathrm{n}=65)\left(\right.$ for pleasure, $M_{\text {Abstract }}=5.405, S D_{\text {Abstract }}=1.097$ versus $M_{\text {Concrete }}=$ 4.631, $S D_{\text {Concrete }}=1.616 ; \mathrm{F}(1,275)=8.732, \mathrm{p}=.003 ; \eta^{2}=.032$; for guilt, $M_{\text {Abstract }}=2.743$, $S D_{\text {Abstract }}=1.434$ versus $M_{\text {Concrete }}=3.430, S D_{\text {Concrete }}=1.992 ; \mathrm{F}(1,275)=6.456, \mathrm{p}=.012 ; \eta^{2}$ $=.023)$. However, for the condition of refraining from buying, differences in both pleasure and guilt between the abstract $(n=68)$ and concrete mindsets $(n=72)$ conditions were insignificant $(\mathrm{F}(1,275)<1.200, \mathrm{p}>.295)$. These results are consistent with $\mathrm{H} 1$ and $\mathrm{H} 2$.

\section{General Discussion}


Across the three studies, we demonstrated that consumers with abstract (vs. concrete) mindsets experienced strong feelings of pleasure, whereas those with concrete (vs. abstract) mindsets experienced higher guilt. These effects were consistently observed in the studies employing different manipulations of mindsets: temporal distance (Study 1), Navon task (Study 2), and the category task (Study 3). Consequently, the results support both $\mathrm{H} 1$ and $\mathrm{H} 2$.

The study results have theoretical implications. First, as reviewed, past studies show that consumers tend to feel both pleasure and guilt after impulse purchases (Gardner and Rook, 1988; Goldsmith et al., 2012; Mukhopadhyay and Johar, 2007). These studies investigated what types of affective states consumers experience after impulsively buying a product. However, they do not consider when the specific emotion (e.g. pleasure and guilt) is strongly felt although psychological literature shows that affective states can vary dynamically (e.g. Larsen 1987). The present research contributed to filling this gap by showing that consumers' construal mindsets can serve as a boundary condition of post-impulse purchase emotion. Addressing this gap has important implications for understanding consumers' emotion after impulse buying for the following reasons.

Impulse buying results in financial waste and psychological effects e.g., guilt or self-hatred (Rook, 1987). Despite such experiences, many consumers, looking back on impulse-buying episodes, do not always have negative feelings (rather, they sometimes think about them positively), and repeat the behaviour (Ramanathan and Williams, 2007). There are many possible reasons for this phenomenon. For example, memories fade with time. However, the phenomenon cannot be explained by forgotten memories alone, which would mean the memory of the impulse-buying episode should fade, resulting not only in weak negative emotions but weak positive feelings. However, as this research (Study 1) demonstrates, feelings of pleasure grow 
stronger over time. A unique feature of this study is its use of construal level theory to provide deeper insights into why consumers experience positive construal about past impulse buys.

This study also contributes to research on post-purchase affective states and construal level theory. As reviewed, marketing studies seem to apply this theory to explain consumer behaviour (e.g. Mantovani et al., 2018; Wright et al., 2011). These studies focus on the impact of consumers' construal levels before purchasing. Some studies observed the impact of construal level mindsets on consumers' responses after purchase, despite several researchers showing that post-purchase affective states are important determinants of satisfaction, word-of-mouth, subsequent decisions, and repurchase intentions (Chitturi et al., 2008; Hasford et al., 2015). Applying construal level theory to post-purchase consumer responses, this study contributed to integrate the two bodies of literature: consumers' construal mindsets and post-purchase emotion.

Finally, the present study contributes to a comprehensive understanding of the relationship between consumers' affective states and impulse purchase. Previous literature shows that negative emotion (e.g., distressed) has no impact on impulse purchase, whereas positive emotion (e.g., excited) serves as a driver of impulse purchase (Beatty and Ferrell 1998; Monhan, Sivakumaran, and Sharma 2013). Contrastingly, our study shows that consumers feel both positive (pleasure) and negative (guilt) emotions after impulse purchase, and these effects were moderated by consumers' construal mindsets. The findings of the past and present studies suggest an asymmetric relationship between pre- and post-impulse purchase behavior can exist.

Besides theoretical implications, this study has managerial implications. First, findings have implications for effective communication that may address post-purchase emotions. The results suggest that immediately after impulse buying, consumers experience intense feelings of guilt. Online shopping has simplified order cancellations and product return policies, just as impulse 
buying has become easier to execute. To counteract this trend, sending appropriate messages, aimed at justifying consumers' purchasing decisions immediately after impulsive buying, is deemed crucial. To do so, marketers can take advantage of consumers' construal mindsets. The literature on construal level theory suggests that advertising message frames can influence consumers' construal mindsets, so a slogan describing the benefit of the product/service (e.g. fitness club) in an abstract manner (e.g. 'enjoy lifelong health') and concrete manner (e.g. 'enjoy daily health activities') makes consumers' mindsets more abstract and concrete, respectively (Wan and Rucker 2013). If so, it could be possible for a company to enhance feelings of pleasure (and decrease guilt) to justify past impulse buying by sending customers a direct mail describing features of the purchased product in an abstract manner (e.g., how the product improves customers' quality life) rather than in concrete manner (e.g., how superior the product's spec is).

This study also offers suggestions for policymakers. Compulsive buying, an addictive shopping behaviour, has become a social problem. If impulse buying is regarded as a dimension of compulsive buying (Hirschman, 1992; Ridgway et al., 2008), policymakers can consider suppressing consumers' impulsive buying behaviour as an important issue. This study's results suggest that after impulse-buying, the feeling of pleasure becomes stronger and guilt declines as the consumer shifts to an abstract mindset. Thus, if a consumer's mindset can be oriented to concrete, then suppressing feelings of pleasure and enhancing guilt could lead to self-restraint in the next impulse-buying episode. For instance, using specific messages to empower consumers to construe their past impulse buying with a concrete mindset (e.g., 'Remember how much you spent for the previous impulse buy') may enhance feelings of guilt and suppress subsequent impulsive buying behaviour.

Businesses conduct satisfaction surveys for feedback on their products and services. This 
study's results suggest that consumers who impulsively purchased products or services are likely to exhibit different affective states depending on the time elapsed since the purchase. This is because the feeling of pleasure after obtaining a product is stronger when the purchase episode is temporally distant compared to temporally close. Therefore, even if the same product or service is purchased, consumers are likely to exhibit stronger satisfaction after a long time has passed since the purchase than immediately after the purchase. Hence, in satisfaction surveys, time elapsed since the purchase is necessary whether the product or service was a planned or impulse purchase. Such measures may control the effect of temporal distance, enabling a more accurate assessment of satisfaction with the purchased product or service.

The current study has several limitations. For instance, although the study focused on relatively high-involvement products, consumers often purchase low-involvement products (e.g. a snack ) on impulse. Therefore, future studies should examine whether our findings are applicable to such low-involvement products. The current study does not examine the impact of effects reported here on subsequent impulse shopping. Future studies should therefore investigate how consumers' psychological distance influences subsequent impulse purchases. To enhance the findings' robustness, experiments involving psychological distances other than temporal distance (e.g. social distance) or focusing on situations other than impulse buying (e.g. overeating or drinking) and post-purchase affective states other than pleasure and guilt (e.g. excitement, happiness, regret) are necessary. 


\section{References}

Alba, J. W., \& Williams, E. F. (2013), "Pleasure principles: A review of research on hedonic consumption", Journal of Consumer Psychology, Vol. 23 No. 1, pp. 2-18.

Beatty, S. E., and Ferrell, M. E. (1998), "Impulse buying: Modeling its precursors", Journal of Retailing, Vol. 74, No. 2, pp. 169-191.

Bell, D. R., Corsten, D., \& Knox, G. (2011), "From point of purchase to path to purchase: How preshopping factors drive unplanned buying”, Journal of Marketing, Vol. 75 No. 1, pp. 3145.

Bornemann, T. and Homburg, C. (2011), "Psychological distance and the dual role of price", Journal of Consumer Research, Vol. 38 No. 3, pp. 490-504.

Bui, M., Krishen, A. S., \& Bates, K. (2011), "Modeling regret effects on consumer post-purchase decisions", European Journal of Marketing, Vol. 45 No. 7/8, pp. 1068-1090.

Chaudhuri, A. and Holbrook, M. B. (2001), "The chain of effects from brand trust and brand affect to brand performance: the role of brand loyalty", Journal of Marketing, Vol. 65 No. 2, pp. 8193.

Chitturi, R., Raghunathan, R. and Mahajan, V. (2007), "Form versus function: how the intensities of specific emotions evoked in functional versus hedonic trade-offs mediate product preferences", Journal of Marketing Research, Vol. 44 No. 4, pp. 702-714.

Chitturi, R., Raghunathan, R. and Mahajan, V. (2008), "Delight by design: The role of hedonic versus utilitarian benefits", Journal of Marketing, Vol. 72 No. 3, pp. 48-63.

Chu, W., Song, M. R., \& Choi, B. (2013), "Post-purchase disadvantages of a less preferred brand and how they can be overcome: an examination of regret and attribution", Journal of Applied Social Psychology, Vol. 43 No.4, pp. 887-898. 
Crawford, G. and Melewar, T. C. (2003), "The importance of impulse purchasing behaviour in the international airport environment”, Journal of Consumer Behaviour, Vol. 3 No. 1, pp. 85-98.

Eyal, T., Liberman, N., Trope, Y. and Walther, E. (2004), “The pros and cons of temporally near and distant action", Journal of Personality and Social Psychology, Vol. 86 No. 6, pp. 781795.

Förster, J., Friedman, R. S. and Liberman, N. (2004), “Temporal construal effects on abstract and concrete thinking: consequences for insight and creative cognition”, Journal of Personality and Social Psychology, Vol. 87 No. 2, pp. 177-189.

Freitas, A. L., Gollwitzer, P. and Trope, Y. (2004), “The influence of abstract and concrete mindsets on anticipating and guiding others' self-regulatory efforts”, Journal of Experimental Social Psychology, Vol. 40 No. 6, pp. 739-752.

Gardner, M. P. and Rook, D. W. (1988), "Effects of impulse purchases on consumers' affective states”, in Houston, M. J. (Ed.), Advances in Consumer Research, 15, Provo, UT, pp. 127130.

Goldsmith, K., Cho, E. K., \& Dhar, R. (2012), "When guilt begets pleasure: the positive effect of a negative emotion”, Journal of Marketing Research, Vol. 49 No.6, pp. 872-881.

Goodman, J. K. and Malkoc, S. A. (2011), "Choosing here and now versus there and later: The moderating role of psychological distance on assortment size preferences", Journal of Consumer Research, Vol. 39 No. 4, pp. 751-768.

Hansen, J., \& Trope, Y. (2013), "When time flies: How abstract and concrete mental construal affect the perception of time", Journal of Experimental Psychology: General, Vol. 142 No. 2, pp. $336-347$.

Hasford, J., Hardesty, D. M., \& Kidwell, B. (2015), "More than a feeling: Emotional contagion 
effects in persuasive communication", Journal of Marketing Research, Vol. 52 No. 6, pp. $836-847$.

He, Y., Chen, Q., \& Alden, D. L. (2016), “Time will tell: managing post-purchase changes in brand attitude", Journal of the Academy of Marketing Science, Vol. 44 No. 6, pp. 791-805.

Hirschman, E. C. (1992), “The consciousness of addiction: Toward a general theory of compulsive consumption", Journal of Consumer Research, Vol. 19 No. 2, pp. 155-179.

Hong, J. and Lee, A. Y. (2010), "Mixed but not torn: the moderating role of construal level in mixed emotions appeals", Journal of Consumer Research, Vol. 37 No. 3, pp. 456-472.

Houben, M., Van Den Noortgate, W., and Kuppens, P. (2015), “The relation between short-term emotion dynamics and psychological well-being: A meta-analysis", Psychological Bulletin, Vol. 141, No. 4, pp. 901-930.

Hui, S. K., Inman, J. J., Huang, Y., \& Suher, J. (2013), “The effect of in-store travel distance on unplanned spending: Applications to mobile promotion strategies", Journal of Marketing, Vol. 77 No. 2, pp. 1-16.

Kacen, J. J. and Lee, J. A., (2002), "The influence of culture on consumer impulsive buying behavior", Journal of Consumer Psychology, Vol. 12, No. 2, pp. 163-176.

Kuppens, P., Oravecz, Z. and Tuerlinckx, F. (2010), "Feelings change: Accounting for individual differences in the temporal dynamics of affect," Journal of Personality and Social Psychology", Vol. 99, No. 6, pp. 1042-1060.

Kyung, E. J., Menon, G. and Trope, Y. (2010), "Reconstruction of things past: Why do some memories feel so close and others so far away"? Journal of Experimental Social Psychology, Vol. 46 No. 1, pp. 217-220.

Larsen, R. J. (1987), “The stability of mood variability: A spectral analytic approach to daily mood 
assessments", Journal of Personality and Social Psychology, Vol. 52, No. 6, pp. 1195-1204.

Leckie, C., Nyadzayo, M. W., and Johnson, L. W. (2016), “Antecedents of consumer brand engagement and brand loyalty”, Journal of Marketing Management, Vol.32 No.5-6, pp.558578.

Lee, H., Deng, X., Unnava, H. R., \& Fujita, K. (2014), “Monochrome forests and colorful trees: The effect of black-and-white versus color imagery on construal level", Journal of Consumer Research, Vol. 41 No. 4, pp. 1015-1032.

Lee, H., Fujita, K., Deng, X., \& Unnava, H. R. (2017), “The Role of temporal distance on the color of future-directed imagery: A construal-level perspective", Journal of Consumer Research, Vol. 43 No. 5, pp. 707-725.

Lee, L., \& Tsai, C. I. (2013), "How price promotions influence post purchase consumption experience over time", Journal of Consumer Research, Vol. 40 No. 5, pp. 943-959.

Liberman, N. and Trope, Y. (2008), "The psychology of transcending the here and now”, Science, Vol. 322 No. 5905, pp. 1201-1205.

MacDonnell, R. and White, K. (2015), “How construals of money versus time impact consumer charitable giving", Journal of Consumer Research, Vol. 42, No. 4, pp. 551-563.

Malhotra, N. K., Kim, S. S., and Patil, A. (2006), "Common method variance in IS research: A comparison of alternative approaches and a reanalysis of past research", Management Science, Vol.52 No.12, pp.1865-1883.

Malhotra, N. K., Schaller, T. K., and Patil, A. (2017), "Common method variance in advertising research: When to be concerned and how to control for it", Journal of Advertising, Vol.46 No.1, pp.193-212.

Mano, H. and Oliver, R. L. (1993), “Assessing the dimensionality and structure of the consumption 
experience: evaluation, feeling, and satisfaction", Journal of Consumer Research, Vol. 20 No. 3, pp. 451-466.

Mantovani, D., Korelo, J.C. and Ibarra, J. (2018), "Effects of brand transgressions on third-party consumers", Marketing Intelligence \& Planning, Vol. 36. No. 3, pp. 306-317.

Martin, B. A., Gnoth, J. and Strong, C. (2009), “Temporal construal in advertising”, Journal of Advertising, Vol. 38 No. 3, pp. 5-20.

Mohan, G., Sivakumaran, B., and Sharma, P. (2013), "Impact of store environment on impulse buying behavior", European Journal of Marketing, Vol. 47, No. 10, pp. 1711-1732.

Mukhopadhyay, A. and Johar, G. V. (2007), "Tempted or not? The effect of recent purchase history on responses to affective advertising", Journal of Consumer Research, Vol. 33 No. 4, pp. 445453.

Navon, D. (1977), "Forest before trees: The precedence of global features in visual perception", Cognitive Psychology, Vol. 9, No. 3, pp. 353-383.

Oliver, R. L. (2010), Satisfaction: A Behavioral Perspective on the Consumer, Second Edition, Routledge, New York.

Oliver, R. L. and Swan, J. E. (1989), "Consumer perceptions of interpersonal equity and satisfaction in transactions: A field survey approach", Journal of Marketing, Vol. 53 No. 2, pp. $21-35$.

Oliver, R. L., Rust, R. T. and Varki, S. (1997), "Customer delight: foundations, findings, and managerial insight", Journal of Retailing, Vol. 73 No. 3, pp. 311-336.

Podsakoff, P. M. and Organ, D. W. (1986), "Self-reports in organizational research: Problems and prospects", Journal of Management, Vol. 12, No. 4, pp. 531-544.

Podsakoff, P. M., Mackenzie, S. B., Lee, J. Y., and Podsakoff, N. P. (2003), “Common method 
biases in behavioral research: A critical review of the literature and recommended remedies", Journal of Applied Psychology, Vol.88 No.5, pp.879-903.

Ramanathan, S. and Williams, P. (2007), "Immediate and delayed emotional consequences of indulgence: The moderating influence of personality type on mixed emotions", Journal of Consumer Research, Vol. 34 No. 2, pp. 212-223.

Richins, M. L. (1997), "Measuring emotions in the consumption experience”, Journal of Consumer Research, Vol. 24 No. 2, pp. 127-146.

Ridgway, N. M., Kukar-Kinney, M. and Monroe, K. B. (2008), “An expanded conceptualization and a new measure of compulsive buying", Journal of Consumer Research, Vol. 35 No. 4, pp. $622-639$.

Rook, D. W. (1987), "The buying impulse”, Journal of Consumer Research, Vol. 14 No. 2, pp. $189-199$.

Rook, D. W. and Fisher, R.J. (1995), "Normative influences on impulsive buying behavior", Journal of Consumer Research, Vol. 22 No. 3, pp. 305-313.

Roseman, I. J. (1991), “Appraisal determinants of discrete emotions”, Cognition \& Emotion, Vol. 5 No. 3, pp. 161-200.

Roseman, I. J., Wiest, C. and Swartz, T. S. (1994), "Phenomenology, behaviors, and goals differentiate discrete emotions", Journal of Personality and Social Psychology, Vol. 67 No. 2, pp. 206-221.

Sultan, A. J., Joireman, J. and Sprott, D.E. (2012), "Building consumer self-control: The effect of self-control exercises on impulse buying urges", Marketing Letters, Vol. 23 No. 1, pp. 61-72.

Trope, Y. and Liberman, N. (2003), “Temporal construal”, Psychological Review, Vol. 110 No. 3, pp. $403-421$. 
Trope, Y., \& Liberman, N. (2010), "Construal-level theory of psychological distance”, Psychological Review, Vol. 117 No. 2, pp. 440-463.

Trope, Y., Liberman, N. and Wakslak, C. (2007), "Construal levels and psychological distance: Effects on representation, prediction, evaluation, and behavior", Journal of Consumer Psychology, Vol. 17 No. 2, pp. 83-95.

Underhill, P. (1999), Why We Buy: The Science of Shopping, Simon and Schuster, New York.

Vallacher, R. R. and Wegner, D. M. (1989), "Levels of personal agency: Individual variation in action identification", Journal of Personality and Social Psychology, Vol. 57 No. 4, pp. 660671.

Wan, E. W. and Rucker, D. D. (2013), “Confidence and construal framing: When confidence increases versus decreases information processing", Journal of Consumer Research, Vol. 39, No. 5, pp. 977-992.

Wright, S., Manolis, C., Brown, D., Guo, X., Dinsmore, J., Peter Chiu, C.Y. and Kardes, F. R. (2012), "Construal-level mind-sets and the perceived validity of marketing claims", Marketing Letters, Vol. 23 No. 1, pp. 253-261.

Xu, J., Jiang, Z., and Dhar, R. (2013), "Mental representation and perceived similarity: How abstract mindset aids choice from large assortments", Journal of Marketing Research, Vol. 50, No. 4, pp. 548-559.

Zeelenberg, M., Nelissen, R. M., Breugelmans, S. M., \& Pieters, R. (2008), “On emotion specificity in decision making: Why feeling is for doing", Judgment and Decision Making, Vol. 3 No. 1, pp. 18-27. 
Figure 1: Two-way interactions: Study 3

(a) Pleasure

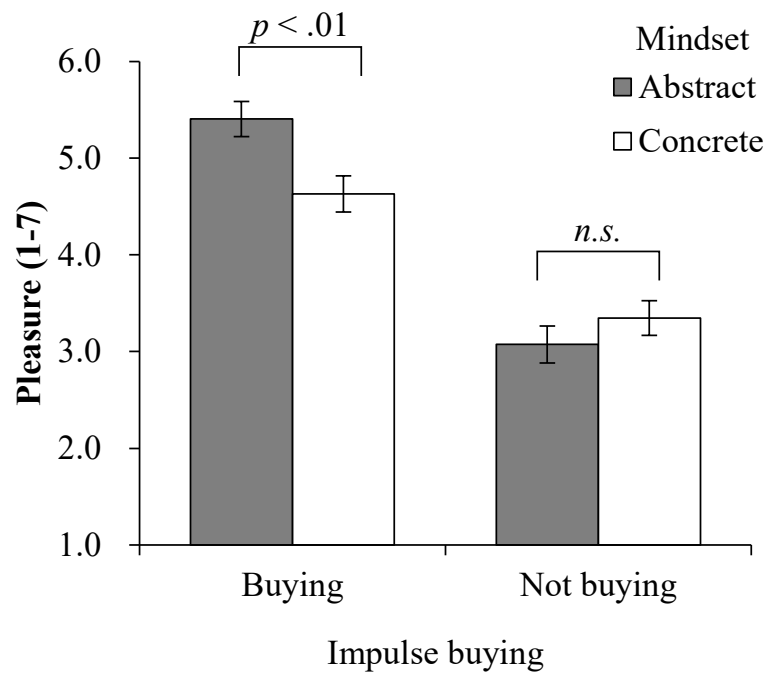

(b) Guilt

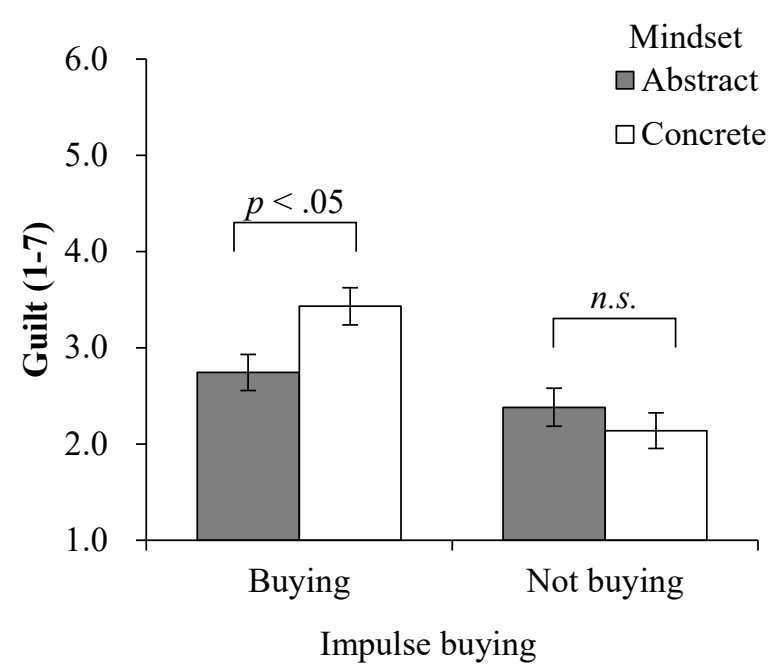


Appendix: Stimulus used in Study 2

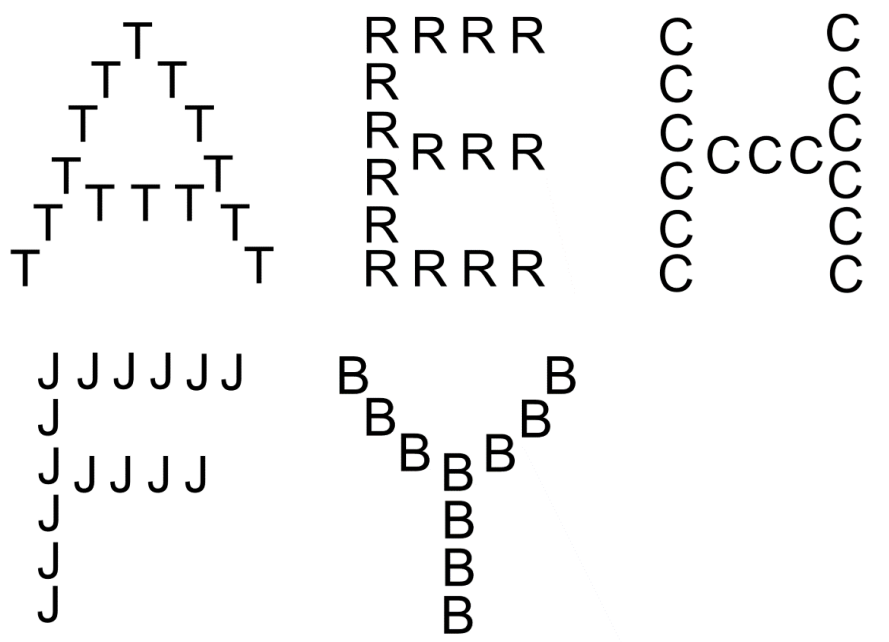

